\title{
Incidence of Major Insect Pests and Natural Enemies in Three Rice Growing Seasons of Bangladesh
}

\author{
S Afrin ${ }^{1}$, M N Bari1, M M M Kabir 1 , A B M A Uddin ${ }^{1}$ and S S Haque ${ }^{1}$
}

\begin{abstract}
Incidence of insect pests and their associated natural enemies was investigated from July 2017- June 2018 at six locations (Gazipur, Rajshahi, Barishal, Sonagazi, Rangpur, Cumilla) of Bangladesh to identify their major occurrence period as well as their incidence in three rice growing seasons, (Aus, T. Aman, and Boro). Among the tested locations, marked differences were found in the composition of insect pest and natural enemies. Higher number of pest population was found at Gazipur with 80,000 individuals for insect pest and 40,000 individuals for natural enemies. At least one peak for major insect pest and natural enemies suggested their specific occurrence period across the locations. Among the insect pests, major peak of GLH was found at Gazipur and Rajshahi during T. Aman season with 4,000 individuals for each location. In contrast, BPH population was as high as 10,000 individuals for Gazipur in October during T. Aman season. Additionally, it was high at Rajshahi in October and November with around 2,000 individuals of BPH. For WBPH, one major peak was found in October at Gazipur and Rajshahi with 10,000 and 2,000 individuals respectively. For YSB, it was higher at Rajshahi in October with over 6,000 individuals during T. Aman season. Moreover, one major peak also observed in Barishal with over 2,000 individuals in November. Among natural enemies, CDB population was observed mainly at three locations in between October and November with 900 individuals for Gazipur, 400 individuals for Rajshahi and 200 individuals for Barishal during T. Aman season. In contrast, for STPD population, two major peaks were found in Barishal with 6,000 and 5,000 individuals in December and March respectively during Boro season. For GMB population, it was observed at Gazipur in November with more than 20,000 individuals during T. Aman season whereas Rajshahi had around 2,000 individuals in the same month. However, higher incidence of GLH, BPH, and WBPH at Gazipur and Rajshahi suggested availability of insect pests during T. Aman season. In contrast, higher YSB incidence at Barishal and Rajshahi indicated their abundance in those areas. On the other hand, incidence of natural enemies at Gazipur indicated presence of greater biological control compared with other locations. In future, this information could serve as a reliable source in strengthening rice pest monitoring services as well as effective pest control in Bangladesh.
\end{abstract}

Keywords: Insect pest, incidence, natural enemies, rice (Oryza sativa L.)

\section{INTRODUCTION}

Bangladesh has three overlapping rice growing seasons in a calendar year, namely Aus, T. Aman, and Boro. Firstly, Boro is corresponding to dry season (November to May) while T. Aman is representative of wet season rice (July to November). In contrast, Aus season falls in between Boro and T. Aman, which extends from April to July (Shelly et al., 2016). As a result, rice is cultivated throughout the year that favours higher population growth of major insect pests of rice as well as their natural enemies (Khan, 2013; Rahman et al., 2017). In general, the fauna which are harmful to rice plant and cause economic loss in paddy fields are termed as insect pests of rice while the fauna which acts as biological control agents of those harmful insect pests are known as beneficial insects (Khan, 2013). These beneficial insects have been categorized as predators and parasitoids, collectively known as natural enemies. Additionally, about only $15 \%$ of the insects in the rice field are herbivores (pest), while the remaining 85\% constitutes detritivores, neutral, beneficial,

${ }^{1}$ Entomology Division, Bangladesh Rice Research Institute, Gazipur 1701. *Corresponding author's E-mail: sadia.afrin0121@gmail.com 
decomposers etc. (Williamson, 1998, Kiritani, 2006, Win et al., 2011).

However, common insect pests of rice include green leaf hopper (GLH), brown plant hopper (BPH), white backed plant hopper $(\mathrm{WBPH})$, and yellow stemborer (YSB). Generally, they also differed from each other in terms of nature of damage in the paddy fields. For instance, both nymphs and adults of GLH feed by extracting plant sap and adult spread the viral disease tungro. In contrast, $\mathrm{BPH}$ cause orange-yellowish leaves before turning brown and dry and this is a condition called hopper burn that kills the plant. Both nymphs and adults of WBPH suck phloem sap causing reduced vigour, stunting, yellowing of leaves and delayed tillering and grain formation. YSB feed upon tillers and causes dead hearts or drying of the central tiller, during vegetative stage; and causes whiteheads at reproductive stage. On the other hand, natural enemies play a greater role in biological control of harmful insect pests. Carabid beetle (CDB), staphylinid beetle (STPD) and green mirid bug (GMB) have been reported as biological control agents of rice pests (Rice Knowledge Bank, 2019; BRKB, 2019).

Generally, rice growers do not apply insecticides in proper doses or appropriate chemical to control those insect pests. This often led to severe reduction of natural enemies. Population dynamics of insect pest and natural enemies in different rice growing seasons could help us to understand incidence pattern of major insect pest as well as their natural enemies which could facilitate biological control rather than chemical control. Moreover, incidence of insect pests and abundance of their natural enemies vary greatly depending on climate and crop growing conditions of each location.

In previous studies, considerable variation of insect pests and natural enemies were observed across multiple locations of Bangladesh (Anonymous, 2016, Ali et al., 2019a). Further investigation is required to observe their abundance and incidence pattern in relation to rice growing seasons. Thus, present study was undertaken to investigate incidence of major insect pest and natural enemies in three rice growing seasons, Aus, $\mathrm{T}$. Aman, and Boro.

\section{MATERIALS AND METHODS}

Rice insect pests and their natural enemies were monitored using light trap across six locations of Bangladesh including Gazipur, Cumilla, Barishal, Rajshahi, Sonagazi and Rangpur. Light trap with certain modifications were incorporated in accordance with essential requirements. The trap had four parts i.e. collecting chamber, funnel shaped lid, light source and a lid from the top to protect from unexpected showers. The light source was a 100W normal electrical bulb, $200 \mathrm{~cm}$ above the ground. The light trap (BRRI, Gazipur, Bangladesh) was constructed in 1973 and has been used since then for monitoring insect pests and natural enemies of rice pests (Ali et al., 2014). Trapped insect pests and natural enemies were collected every day, recorded and deposited along with monthly total tallies for July 2017 to June 2018.

\section{RESULTS AND DISCUSSIONS}

\section{Total pest population in the tested locations}

Among the tested locations, marked differences were found in the composition of insect pest and natural enemies (Fig. 1). Firstly, Gazipur had higher number of pest population followed by Rajshahi and Barishal. For Gazipur, pest population consisted of more than 80,000 insect pest individuals with around 40,000 individuals of natural enemies. In case of Rajshahi, it was approximately 55,000 individuals for insect pest and 10,000 individuals for natural enemies. But, Barishal 


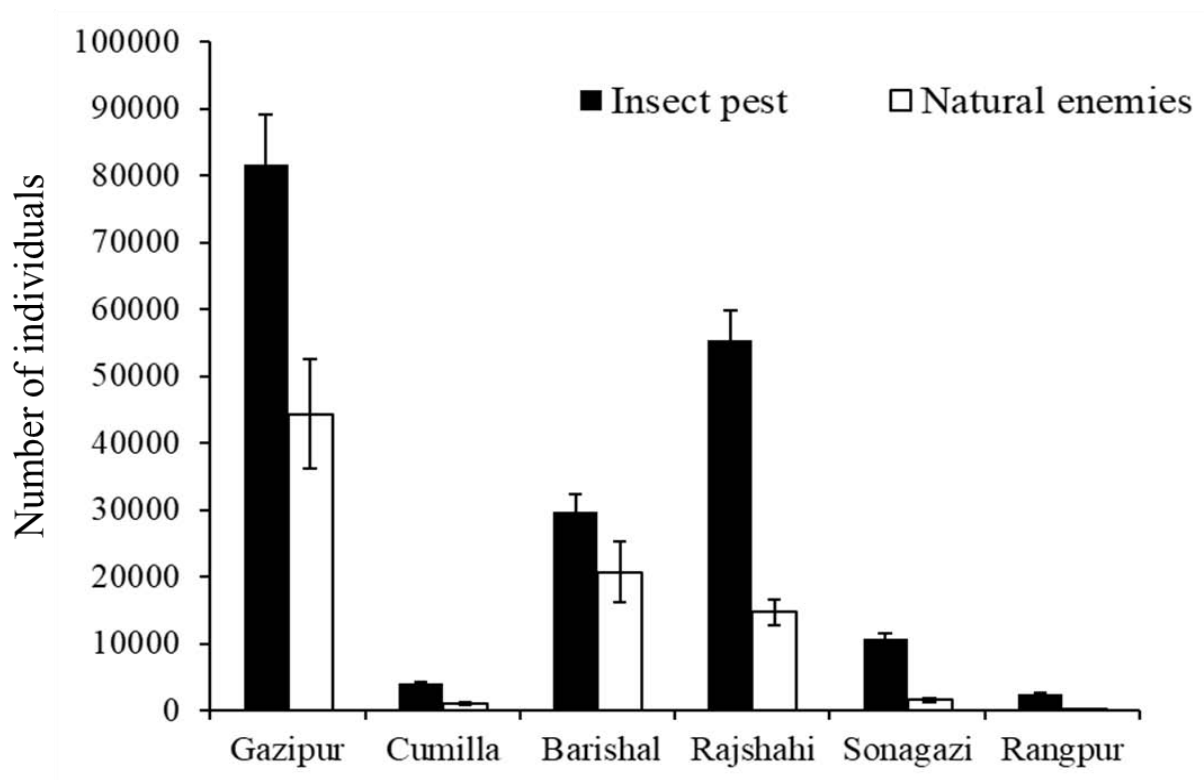

Fig. 1. Bar represents total number of insect pest and natural enemies (mean \pm SD) from July 2017 to June 2018.

Note: Insect pests include total number of individuals of green leafhopper, white leafhopper, orange headed leafhopper, zigzag leafhopper, brown planthopper, white-backed planthopper, yellow stem borer, dark headed borer, pink borer, gall midge, rice leafroller, caseworm, grass hopper, short horn grasshopper, long horn grasshopper, long horn cricket, mole cricket, field cricket, swarming caterpillar, rice hispa, rice bug, small brown planthopper and scotinophora bug. natural enemies include carabid beetle, ladybird beetle, staphylinid beetle, green mired bug, damselfly, spider, ear wig, tiger beetle, elaterid beetle, dragon fly, and ground beetle.

had nearly similar composition with around 30,000 individuals for insect pest and 20,000 individuals for natural enemies. Compared to above three locations, smaller amount of pest population was present in Cumilla, Sonagazi, and Rangpur during the study period with less than 10,000 individuals for each location.

\section{Incidence of major insect pests in different locations}

For GLH, two peaks were observed during the pest monitoring period July 2017 to June 2018 (Fig. 2A). First peak was found at two locations in October with around 10,000 individuals for Gazipur and around 2,000 individuals for Rajshahi. However, a second peak was observed at the end of April for Gazipur with less than 1,500 GLH individuals. No major peaks were found for GLH population in the remaining locations.
For BPH population, major peak was found in October for Rajshahi with more than 6,000 individuals while November for Barishal with around 2,000 individuals (Fig. 2B). In case of WBPH population major peak was found for three locations in October for Gazipur and Rajshahi while November for Barishal with same number of individuals (Fig. 2C). Like $\mathrm{BPH}$, both Gazipur and RS Rajshahi had one peak in October with a WBPH population around 10,000 and 2,000 respectively (Fig. 2C). For YSB, Rajshahi and Barishal showed two major peaks at different times for each location (Fig. 2D). It was found in October and May for Rajshahi with around 6,000 and 3,200 YSB individuals respectively. In case of Barishal, two peaks were observed in November and March with 2,200 and 1,000 YSB individuals respectively. 


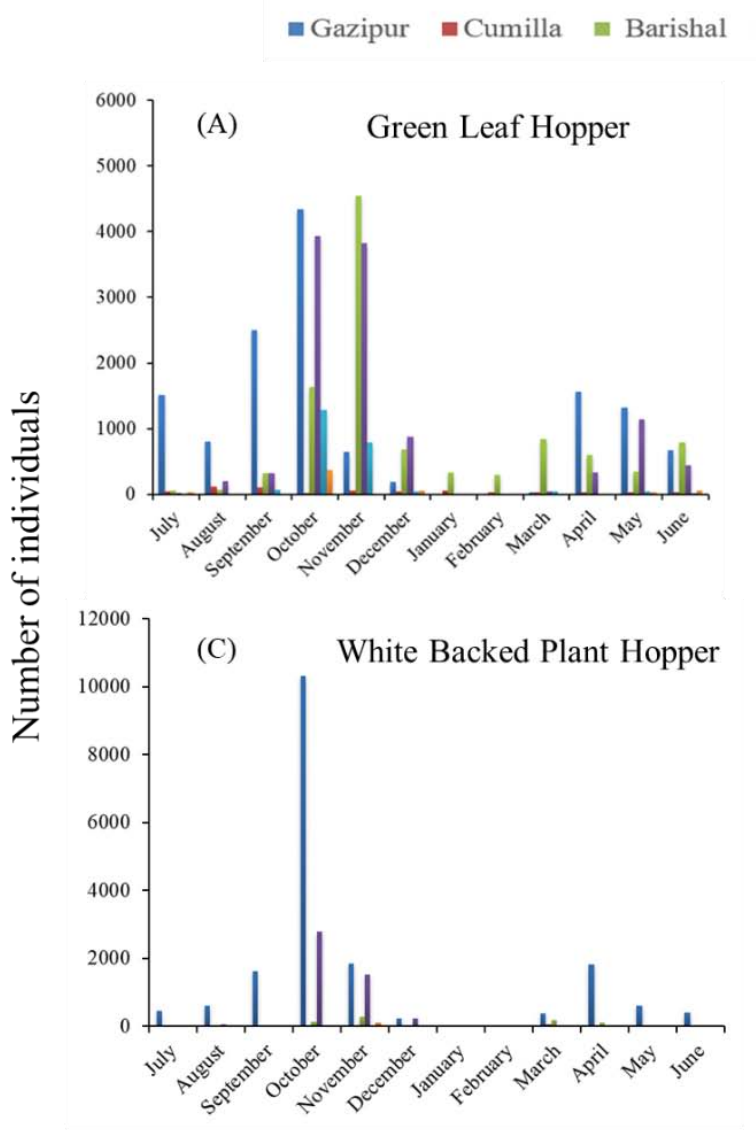

= Rajshahi $=$ Sonagazi $=$ Rangpur
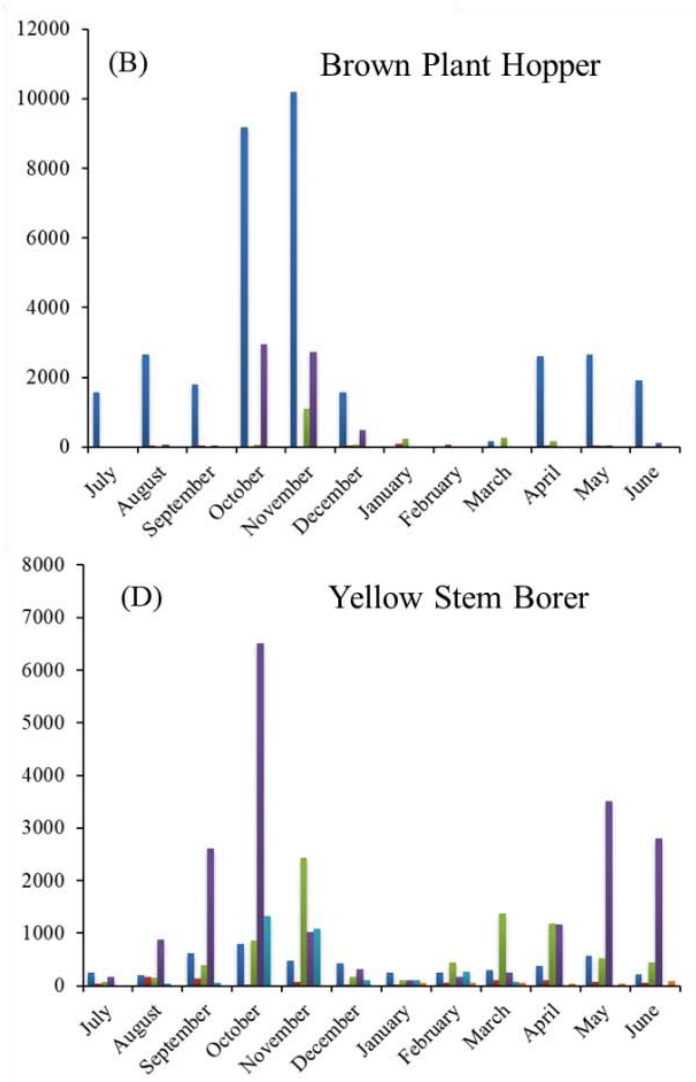

Fig. 2. Incidence of major insect pests including green leafhopper, brown plant hopper, white backed planthopper and yellow stem borer individuals from July 2017 to June 2018 across six locations namely Gazipur, Cumilla, Barishal, Rajshahi, Sonagazi, and Rangpur.

\section{Distributions of natural enemies in different locations}

For CDB, major peaks were found at three locations, Gazipur, Rajshahi and Barishal (Fig. 3A). In Gazipur, peaks were found in November and May with around 900 and 400 CDB individual, respectively. For CDB population, Rajshahi had major peaks in October while March for Barishal with 400 individuals. Furthermore, Cumilla had one peak with around 200 individuals in February.

For STPD population, major peaks were found at Barishal in December at Barishal with 6,000 individuals whereas around 3,000 individuals for Gazipur in the same month
(Fig. 3B). Rajshahi had major peak in March with around 1,000 individuals. For GMB, one major peak was observed at Gazipur with more than 20,000 GMB individuals in November (Fig. 3C).

Fluctuations of major insect pests in three rice growing seasons

In Aus season, there was less incidence of GLH in the observed locations (Fig. 4a). Less population was observed only at Gazipur in May and July with 1,200 and 1,500 individuals respectively. In T. Aman season, one major peak was found at three locations in different months. Gazipur and Rajshahi had around 4,000 individuals in October while over 4,000 


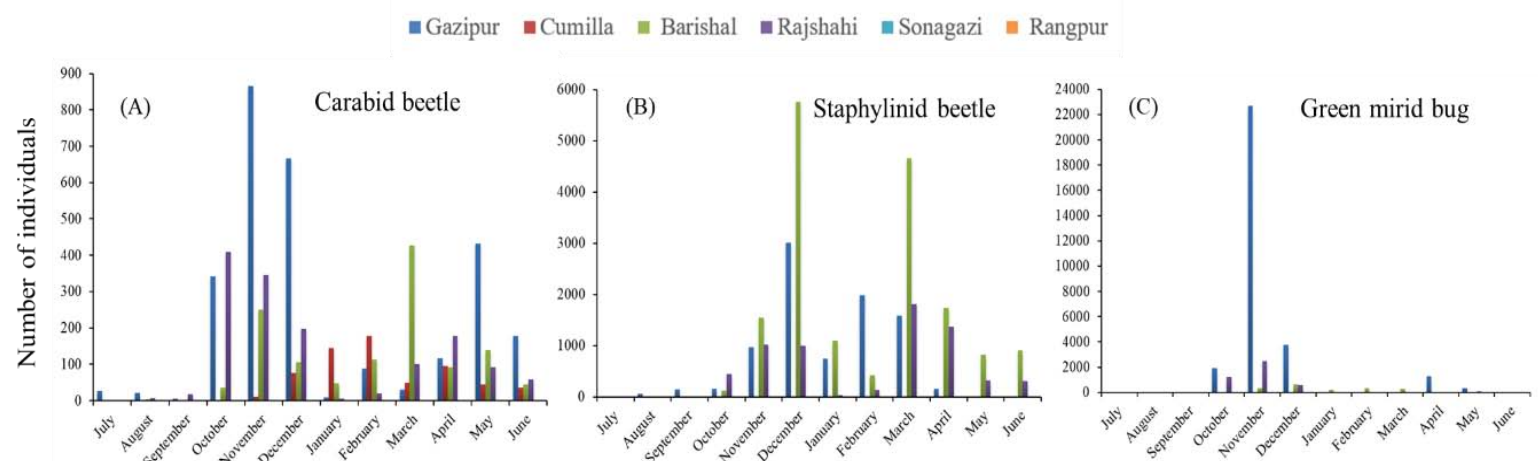

Fig. 3. Incidence of major natural enemies including carabid beetle, staphylinid beetle, and green mirid bug individuals from July 2017 to June 2018 across six locations namely Gazipur, Cumilla, Barishal, Rajshahi, Sonagazi, and Rangpur.

individuals for Barishal in the month of November. Like Aus, less incidence of GLH was found in the Boro season with less than 1,000 individuals in the observed locations. Among the locations, incidence of BPH was less in the Aus season (Fig.4a). Among all locations, Gazipur had presence of $\mathrm{BPH}$ individuals with a static manner throughout the season. In the same location, $\mathrm{BPH}$ population was as high as 10,000 individuals in T. Aman season in the month of October and it increased sharply in November. Similarly, it was high at Rajshahi in October and November with over 2,000 individuals. There was no incidence of $\mathrm{BPH}$ population at other locations. Like Aus, incidence of $\mathrm{BPH}$ population was less among evaluated locations in the Boro season.

There was no incidence of WBPH population in Aus season (Fig. 5b). In T. Aman, one major peak was observed in October at Gazipur and Rajshahi with 10,000 and 2,000 individuals respectively. Like Aus, there was no incidence of WBPH in Boro season. In Aus, higher incidence of YSB was found at Rajshahi in May with around 3,500 individuals (Fig. 5b). In T. Aman, one major peak was observed in the same location with over 6,000 individuals in October. Moreover, one major peak also observed in Barishal with over 2,000 individuals in November. In Boro, one major peak was observed with 1,000 individuals in Barishal and Rajshahi in March and April respectively.
Fluctuations of major natural enemies in three rice growing seasons

In Aus season, CDB population was present only in Gazipur with around 400 individuals. In T. Aman, one major peak was observed at three locations in between October and November with 900 individuals for Gazipur, 400 individuals for Rajshahi, and 200 individuals for Barishal. In Boro season, CDB population was present among the locations with certain fluctuations throughout the time period. One major peak was found at Gazipur in December and at Barishal in March with 700 and 400 individuals respectively.

In Aus season, there were few incidences of STPD population in the observed locations (Fig. 6). It was present at Rajshahi and Barishal in the month of May and June with less than 1000 individuals. In T. Aman, similar incidence of STPD was found at Gazipur, Rajshahi, and Barishal in the month of November with same number of individuals. In Boro season, the population of STPD varied greatly across the locations. Two major peaks were found in Barishal with 6,000 and 5,000 individuals in the month of December and March respectively. Similarly, Gazipur and Rajshahi had two major peaks in December and February for Gazipur, and December and March for Rajshahi. The population varied between 1,000-3,000 individuals at those locations. 


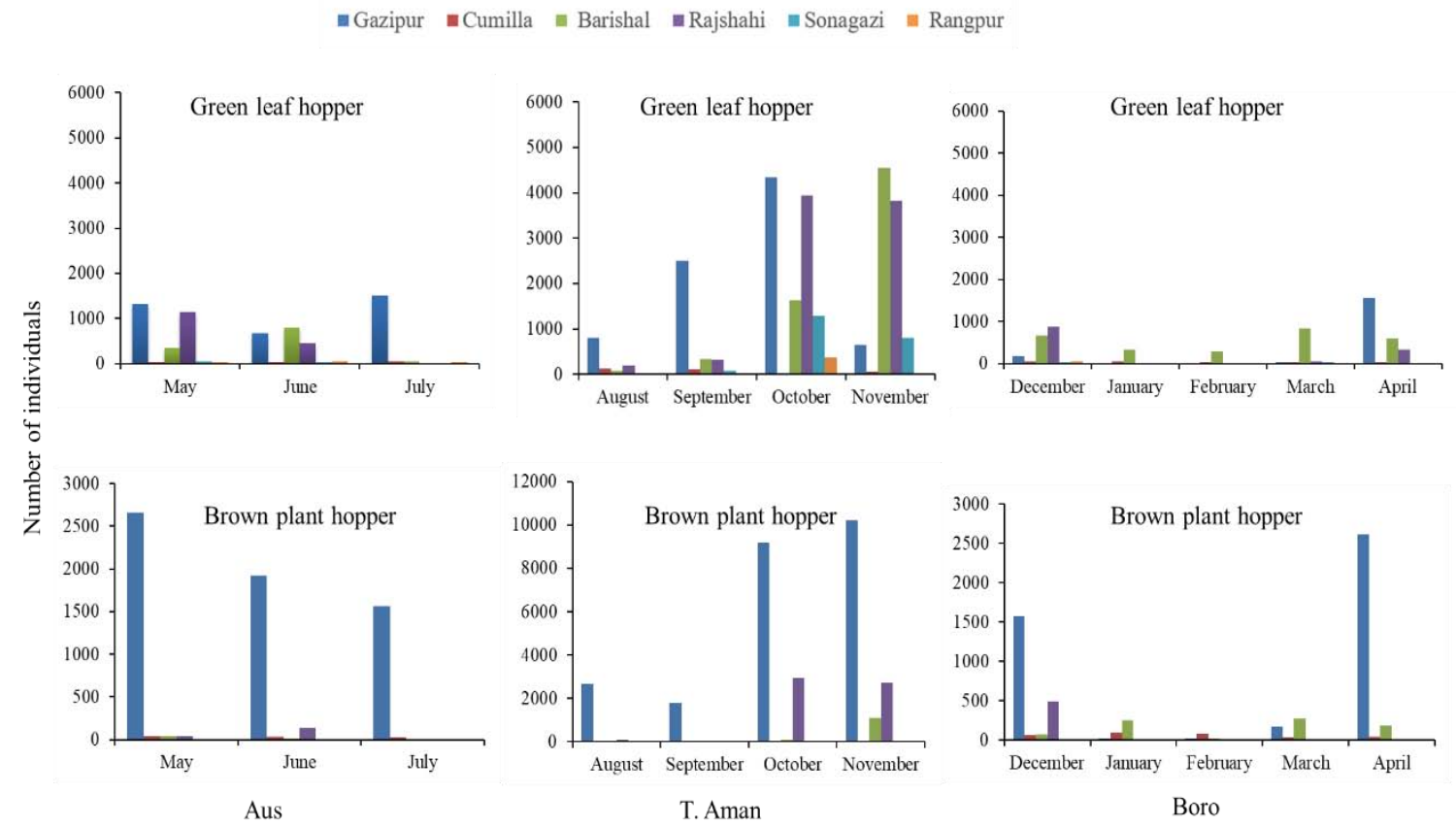

Fig. 4. Incidence of major insect pest in three rice growing seasons Aus, T. Aman and Boro. Data from May to July represent Aus, May to July represent T. Aman, and December to April represent Boro season.

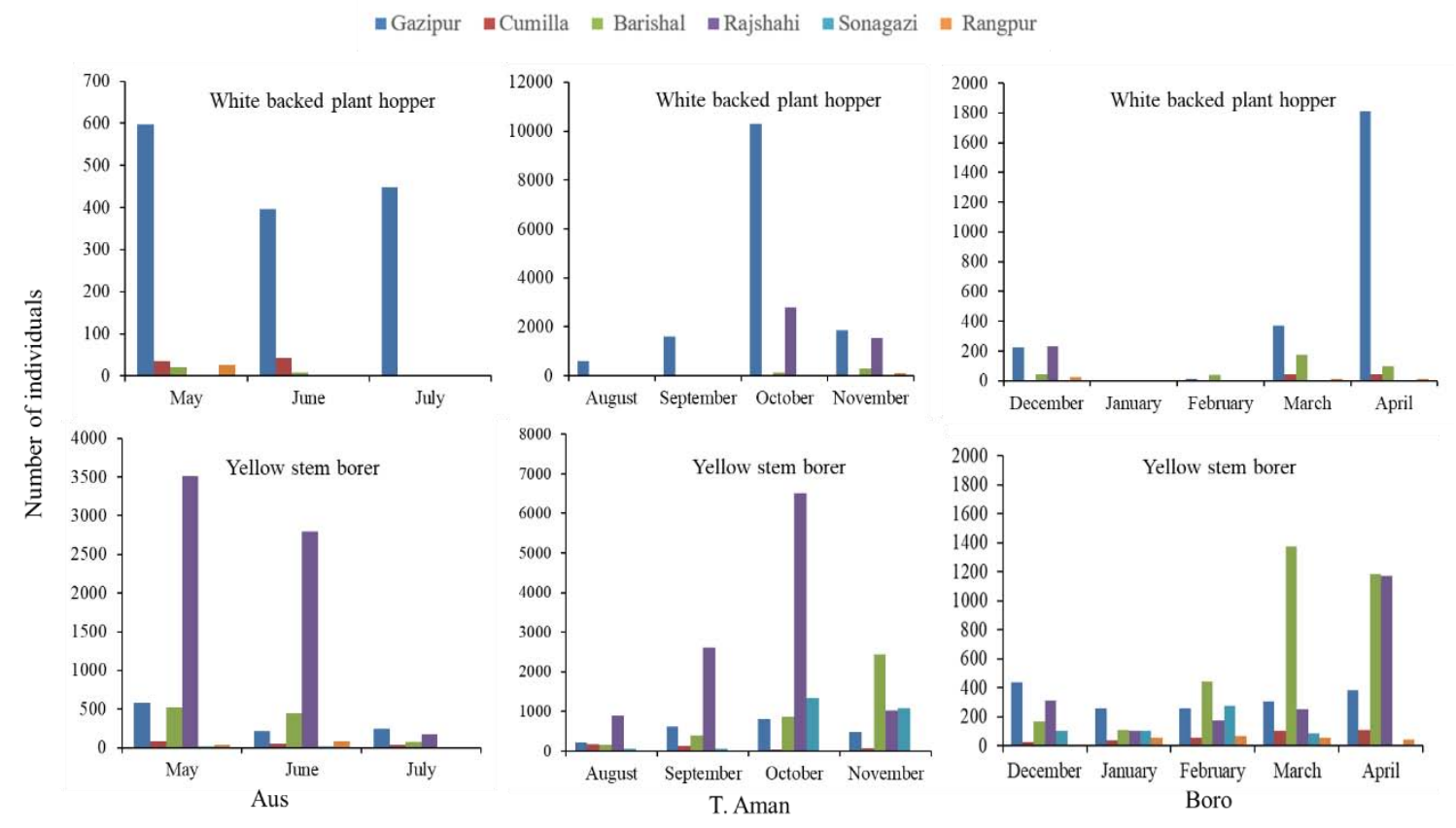

Fig. 5. Incidence of major insect pest in three rice growing seasons Aus, T. Aman and Boro. Data from May to July represent Aus, May to July represent T. Aman, and December to April represent Boro season. 


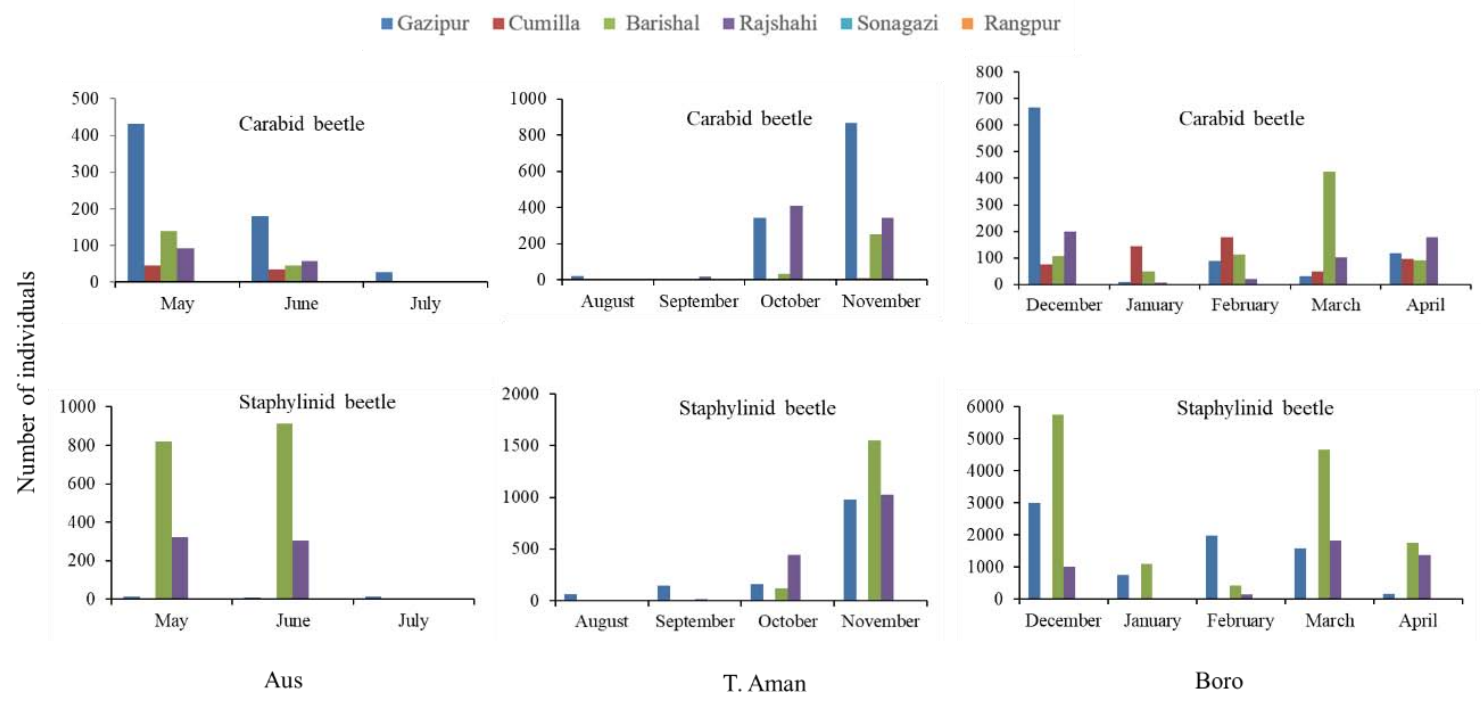

Fig.6. Incidence of major natural enemies in three rice growing seasons Aus, T. Aman and Boro. Data from May to July represent Aus, May to July represent T. Aman, and December to April represent Boro season.

In Aus season, GMB incidence was only observed at Gazipur and Rajshahi in May with 380 and 100 individuals respectively. In T. Aman season, unusual pattern of GMB incidence was observed at Gazipur in November with more than 20,000 individuals. In comparison, Rajshahi had around 2,000 individuals on the same month. In Boro, one major peak was observed at Gazipur in December with around 4,000 individuals. Similarly, Rajshahi and Barishal had incidence of GMB in the same month with less than 1,000 individuals.

\section{DISCUSSIONS}

Presence of higher number of pest population (insect pest and natural enemies) in three locations, Gazipur, Barishal, and Rajshahi suggested possibility of pest outbreak in above locations. Later, occurrence period of major insect pests (GLH, BPH, WBPH, and YSB) and natural enemies (CDB, STPD, and GMB) were described based on three rice growing seasons. These findings enable us to figure out the incidence pattern of major insect pests of rice in different locations which could help us to take location specific control measures against major insect pests.

In this study, the total pest population varied greatly from location to location which clearly indicate that incidence of pest population depends on environmental factors. Moreover, presence of natural enemies was coupled with presence of insect pests. For example, Gazipur had 40,000 individuals of natural enemies, which is nearly half of the total insect pests (Fig. 1). These results indicate existence of biological control of insect pest under natural field condition. Similar trend was observed in Barishal. But, Rajshahi had fewer number of natural enemies compared to total insect pests which indicates less existence of natural control in the paddy fields. In previous reports, major incidence of insect pests and natural were also found at three locations, Gazipur, Rajshahi, and Barishal (Anonymous 2016).

In Gazipur and Rajshahi, GLH had major occurrences in October whereas it was November for Barishal (Fig.2). In case of BPH and $\mathrm{WBPH}$, it was found in Gazipur and 
Rajshahi during same period of the calendar year. These results indicate that incidence of GLH, BPH, and WBPH occurred at the same time. However, incidence of YSB was much different from above three insect pests. It was higher in number at Barishal and Rajshahi with 6,000 individuals on October and 2,200 individuals on November. These results clearly indicate that incidence of YSB occurred in Rajshahi and Barishal at different times with greater number of YSB population in Rajshahi. In the reporting year from 2013- 2017, it was also observed that GLH, BPH, and WBPH population are always higher for Gazipur while YSB population showed major occurrence in Rajshahi (Anonymous 2016).

Among natural enemies, CDB, STPD, and $G M B$ were abundant in major three locations. Higher incidence of CDB was found in Gazipur followed by Rajshahi, Barishal and Cumilla. Similarly, STPD population was also high in Gazipur, Barishal and Rajshahi and their occurrences were observed at different periods. These results indicate the presence of natural enemies in above locations which could have significant role in biological control of harmful insect pests of rice. However, GMB population was abundant at Gazipur in November only. These results suggested the existence of fewer GMB populations across locations. Like insect pests, higher incidences of natural enemies were also found at Gazipur with a major peak for GMB at Gazipur (Anonymous 2016).

In the present study, comparison of pest population incidence among rice growing seasons enables us to discuss availability of insect pests and natural enemies in observed locations. Moreover, occurrence of location specific pest population incidence supported the benefit of present study in crop protection programme. During T. Aman season higher incidence of GLH, BPH, and WBPH was found in Gazipur and Rajshahi. Thus, insect pest monitoring and control measures should be strengthened in T. Aman season to minimize the pest damage in those areas. In case of YSB, we observed different scenario in the observed locations. Major occurrences of YSB took place in Rajshahi with higher number of YSB population in all rice growing seasons. In addition, similar trend was also observed in Barishal, mostly in T. Aman and Boro season. Thus, crop protection measures in Barishal should include effective control measures against YSB to minimize the crop loss.

Among natural enemies, CDB and GMB were present in higher number at Gazipur across all the rice growing seasons (Fig. 6). However, major occurrences were observed in T. Aman season. These results clearly indicate possible occurrence of biological control and existence of natural harmony in respect of pest control in rice. Thus, pesticide use should be avoided in possible cases to maintain this ecological balance in every rice production system. Thus, it could help in facilitating biological control in the crop fields. Through conserving natural enemies, a recent example of implementing ecological approaches in Bangladesh suggested reduction of production costs and chemical inputs in the rice ecosystems which could reduce pest infestations in the paddy fields (Ali et al., 2019b). Thus, this information about natural enemies could help us in developing on farm eco-friendly approaches to control major insect pests of rice by reducing chemical usage.

\section{CONCLUSIONS}

In this study, higher number of population in Gazipur, Rajshahi, and Barishal suggested higher incidence of insect population in the rice growing period. Frequent peaks for major insect pests and natural enemies in a specific month suggested incidence of insect 
population in both the seasons. Among three rice growing seasons, T. Aman had higher incidence of insect pest and natural enemies across the observed locations. Additionally, presence of higher number of insect pest in October indicated most favourable time of pest emergence in the calendar year. Moreover, fluctuations of natural enemies among the growing seasons indicated possibility of biological control against major insect pests. In future, location specific population study in multiple years could enable us to find and discuss existing relationship between major insect pests and natural enemies.

\section{REFERENCES}

Afrin, S, A Latif, N M A Banu, M M M Kabir, S S Haque, M M E Ahmed, N N Tonu, and M P Ali. 2017. Intercropping Empower Reduces Insect Pests and Increases Biodiversity in Agro-Ecosystem. Agri. Sci. 8, 1120-1134.

Ali, M P, D Huang, G Nachman, N Ahmed, M A Begum and M F Rabbi. 2014. Will climate change affect outbreak patterns of planthoppers in Bangladesh? PLoS ONE, 9(3).

Ali, M P, M M M Kabir, S Afrin, F Nowrin, S S Haque, M M Haque, A Hashem, B Tabassum, E F AbdAllah, and B R Pittendrigh. 2019a. Increased temperature induces leaf folder outbreak in rice field. J. Appl. Entomol. 00:1-8.
Ali, M P, M N Bari, S S Haque, M M M Kabir, S Afrin, F Nowrin, M S Islam, D A Landis. 2019b. Establishing next-generation pest control services in rice fields: eco-agriculture. Sci. Rep. 9:10180.

Anonymous 2016. Annual Report of Bangladesh Rice Research Institute 2015-2016, BRRI, Gazipur 1701, Bangladesh, pp: 101-104.

BRKB, Bangladesh Rice Knowledge Bank, Accessed 12th October 2019, http:/ / knowledgebank-brri.org

Khan, M M H. 2013. Abundance and diversity of insect pests and natural enemies in coastal rice habitat.Bangladesh J. Entomol. 23(1):89-104.

Kiritani, K. 2006. Predicting impacts of global warming on population dynamics and distributions of arthropods in Japan. Popul. Ecol. 48:5-12.

Rahman, M, M A Maleque, M S Uddin and J Ahmed. 2017. Abundance and Diversity of Beneficial Insect and Spider Species on Rice Ecosystem In Sylhet Region, J. Sylhet Agril. Univ. 4(1):63-70.

Rice Knowledge Bank, Accessed 20 th $^{\text {th }}$ October 2019, http://www.knowledgebank.irri.org/ step-by-stepproduction/growth/pests-and-diseases/insects

Shelly, I J, M Takahashi-Nosaka, M Kano-Nakata, M S Haque and Y Inukai. 2016. Rice Cultivation in Bangladesh: Present Scenario, Problems, and Prospects, J Intl Cooper Agric Dev, 14: 20-29.

Williamson, S. 1998. Understanding natural enemies; a review of training and information in the practical use of biological control. Biocontrol News and Information. 19(4):117-126.

Win, S S, R Muhamad, Z A M Ahma, N A Adam. 2011. Population fluctuations of brown planthopper, Nilaparvata lugens Stal. and white backed planthopper, Sogatella furcifera Horvath on rice. J Entomol 8: 183-190. 
